Journal of Mathematics and Statistics 8 (3): 323-329, 2012

ISSN 1549-3644

C 2012 Science Publications

\title{
Finding the Envelope and Efficient Frontier of Financial Assets
}

\author{
${ }^{1}$ Farida Kachapova and ${ }^{2}$ Ilias Kachapov \\ ${ }^{1}$ School of Computing and Mathematical Sciences, \\ Faculty of Design and Creative Technology, Auckland University of Technology, New Zealand \\ ${ }^{2}$ Examination Academic Services, University of Auckland, Auckland, New Zealand
}

\begin{abstract}
Problem statement: One of the problems considered in financial mathematics is finding portfolios of given financial assets that minimize risk for targeted returns. The set of such portfolios is called the envelope of the assets. Traditionally this problem is solved as a calculus minimization problem involving partial derivatives and Lagrange multipliers. Approach: In this study we describe an invariant geometric solution that uses orthogonal projection in Euclidean space of random variables. Results: The method is applied to find the efficient portfolio and feasible region of the assets and to investigate the mean-variance relation for envelope portfolios. In particular, it is shown that the graph of this relation is the right branch of a hyperbola. The method is illustrated by an example with four financial assets. Conclusion/Recommendation: The described geometric approach can help to improve the teaching of portfolio analysis by making the concept of envelope clearer and by simplifying proofs.
\end{abstract}

Key words:Teaching portfolio analysis, envelope, efficient frontier, feasible set, mean-variance relation, envelope portfolio

\section{INTRODUCTION}

Portfolio analysis investigates how investors can maximize return and minimize risk by spreading their investments over several financial assets and combining them in optimal proportions. Such optimal portfolios make the envelope of the given assets. The problem of finding envelope is described in financial textbooks. Textbooks on financial modelling (for example, Benninga and Czaczkes, 2000; Francis and Taylor, 2000) often do not provide mathematical justification of the solution. In other cases (Teall and Hasan, 2002; Cheang and Zhao, 2005; Kachapova and Kachapov, 2005 ; 2006) the problem is solved as a calculus minimization problem in coordinate form. This traditional solution is quite long and involves the inverse of covariance matrix. Here we suggest an invariant geometric solution that uses orthogonal projection in Euclidean space of random variables. There are many publications that consider practical models in portfolio optimization. The purpose of our article is to improve the teaching of some topics in portfolio analysis by applying general mathematical concepts and improving proofs; the article builds on our previous study in this area (Kachapova and Kachapov, 2010).
The rest of the introduction introduces some concepts and notations of portfolio analysis. Next we describe the geometric method of finding the envelope of financial assets. Then the result is applied to describe the mean-variance relation for envelope portfolios and efficient portfolios and to identify the portfolio with lowest risk. At the end this theory is illustrated by an example with four financial assets.

Portfolio analysis studies random variables, which are returns from investments. Here $\mathrm{N}$ financial assets $A_{1}, A_{2}, \ldots, A_{N}$ are fixed. The return from asset $A_{k}$ is denoted by $r_{k}$. These are its numerical characteristics:

- Expectation $\mu_{k}=\mathrm{E}\left(r_{k}\right)$,

- Variance $\sigma_{\mathrm{k}}^{2}=\operatorname{Var}\left(\mathrm{r}_{\mathrm{k}}\right)$ and

- Covariance $\sigma_{\mathrm{kj}}=\operatorname{Cov}\left(\mathrm{r}_{\mathrm{k}}, \mathrm{r}_{\mathrm{j}}\right)$.

We use the following matrix notations:

- $\mathrm{U}=\left[\begin{array}{llll}1 & 1 & \ldots & 1\end{array}\right]$, the row of units of length $\mathrm{N}$;

- $\quad \mathrm{M}=\left[\begin{array}{llll}\mu_{1} & \mu_{2} & \ldots & \mu_{\mathrm{N}}\end{array}\right]$, the row of the expectations, where at least two values are different (then $U$ and $\mathrm{M}$ are independent);

Corresponding Author: Farida Kachapova, School of Computing and Mathematical Sciences, Faculty of Design and Creative Technology, Auckland University of Technology, New Zealand 
- $\mathrm{S}=\left[\sigma_{\mathrm{ij}}\right]$, the covariance matrix of $\mathrm{A}_{1}, \mathrm{~A}_{2}, \ldots, \mathrm{A}_{\mathrm{N}}$.

We assume that the matrix $S$ is defined and has a non-zero determinant. This implies that $S$ is positive definite, due to the properties of covariance matrix.

Portfolio is a combination of the assets $A_{1}, \ldots, A_{N}$. Any portfolio $\mathrm{x}$ is identified with its return also denoted $\mathrm{x}$. The expectation $\mu=\mathrm{E}(\mathrm{x})$ is the portfolio's expected return; the portfolio's risk is measured by its variance $\sigma^{2}=\operatorname{Var}(\mathrm{x})$. For each $\mathrm{k}=1, \ldots, \mathrm{N}$, denote $\mathrm{x}_{\mathrm{k}}$ the proportion of $A_{k}$ in the total value of $x$; negative values of $x_{k}$ correspond to short sales. Thus, for any portfolio $\mathrm{x}$ Eq. 1:

$$
\mathrm{x}=\sum_{\mathrm{k}=1}^{\mathrm{N}} \mathrm{x}_{\mathrm{k}} \mathrm{r}_{\mathrm{k}} \text { And } \mathrm{x}_{1}+\ldots+\mathrm{x}_{\mathrm{N}}=1
$$

Denote $\mathrm{H}$ the set of all random variables, which are linear combinations of $r_{1}, \ldots, r_{N}$. With operations of addition and scalar multiplication, the set $\mathrm{H}$ is an $\mathrm{N}$ dimensional linear space with a basis $\mathrm{r}_{1}, \ldots, \mathrm{r}_{\mathrm{N}}$. The operation $(\mathrm{x}, \mathrm{y})=\mathrm{E}(\mathrm{x} \cdot \mathrm{y})$ is a scalar product in $\mathrm{H}$, so $\mathrm{H}$ is a Euclidean space. The length of a vector $\mathrm{x}$ is defined as $\|\mathrm{x}\|=\sqrt{(\mathrm{x}, \mathrm{x})}=\sqrt{\mathrm{E}\left(\mathrm{x}^{2}\right)}$. This approach to random variables as vectors in linear space is briefly described in the textbook by Grimmett and Stirzaker (2001).

By (1), any portfolio $\mathrm{x}$ is an element of $\mathrm{H}$ :

$$
\mathrm{x}=\left[\begin{array}{c}
\mathrm{x}_{1} \\
\cdots \\
\mathrm{x}_{\mathrm{N}}
\end{array}\right] .
$$

Theorem 1: For any portfolios $x=\left[\begin{array}{c}x_{1} \\ \ldots \\ x_{N}\end{array}\right], y=\left[\begin{array}{c}x_{1} \\ \ldots \\ x_{N}\end{array}\right]$ :

a) $\mathrm{E}(\mathrm{x})=\mu_{1} \mathrm{x}_{1}+\ldots+\mu_{\mathrm{N}} \mathrm{x}_{\mathrm{N}}=\mathrm{Mx}$;

b) $\operatorname{Var}(x)=x^{T} S x$;

c) $\operatorname{Cov}(x, y)=x^{T} S y$.

Here $\mathrm{x}^{\mathrm{T}}$ means the transpose of $\mathrm{x}$.

Definitions of envelope and efficient frontier: Generally portfolios with higher expected returns carry higher risks. However, it is possible to identify, among all portfolios with the same expected return, a portfolio with lowest risk, i.e., lowest variance.

Definition 1: A portfolio is called an envelope portfolio if it has the lowest variance among all portfolios with the same expected return.
An envelope portfolio minimizes risk for a given targeted return.

Note: all portfolios considered here are combinations of the $\mathrm{N}$ fixed assets $\mathrm{A}_{1}, \ldots, \mathrm{A}_{N}$ as mentioned before.

Definition 2: The set of all envelope portfolios is called the envelope of the assets $A_{1}, \ldots, A_{N}$ and is denoted $\operatorname{Env}\left(A_{1}, \ldots, A_{N}\right)$.

Definition 3: A portfolio is called an efficient portfolio if it has the highest expected return among all portfolios with the same variance.

An efficient portfolio maximizes expected return for a given risk.

Definition 4: The set of all efficient portfolios is called the efficient frontier of the assets $A_{1}, \ldots, A_{N}$ and is denoted EF $\left(\mathrm{A}_{1}, \ldots, \mathrm{A}_{\mathrm{N}}\right)$.

A vector $\mathrm{x}=\left[\begin{array}{c}\mathrm{x}_{1} \\ \ldots \\ \mathrm{x}_{\mathrm{N}}\end{array}\right]$ is an envelope portfolio if it is a solution of the following minimization problem Eq. 2:

$\left\{\begin{array}{c}\operatorname{Var}(\mathrm{x}) \rightarrow \min \\ \mathrm{x}_{1}+\ldots+\mathrm{x}_{\mathrm{N}}=1 \\ \mathrm{E}(\mathrm{x})=\mu\end{array}\right.$

for some fixed real number $\mu$.

Finding the envelope of financial assets: The problem (2) can be solved as a calculus problem in coordinate form using partial derivatives and Lagrange multipliers. Instead we will apply orthogonal projection in the Euclidean space $\mathrm{H}$ to produce an invariant geometric solution.

First we remind the reader some basic facts from linear algebra.

An affine subspace $\mathrm{Q}$ of a linear space $\mathrm{L}$ is a set of the form $Q=\{q+w \mid w \in W\}$, where $q \neq \mathbf{0}$ is a fixed vector and $\mathrm{W}$ is a linear subspace of $\mathrm{L} ; \mathrm{Q}$ is independent of the choce of $\mathrm{q}$.

Denote $\operatorname{Proj}_{\mathrm{W}} \mathrm{x}$ the orthogonal projection of $\mathrm{x}$ onto W. The orthogonal projection has this expression in an orthogonal basis $\mathrm{v}_{1}, \ldots, \mathrm{v}_{\mathrm{n}}$ in W Eq. 3:

$$
\operatorname{Proj}_{\mathrm{W}} \mathrm{x}=\frac{\left(\mathrm{x}, \mathrm{v}_{1}\right)}{\left(\mathrm{v}_{1}, \mathrm{v}_{1}\right)} \mathrm{v}_{1}+\ldots+\frac{\left(\mathrm{x}, \mathrm{v}_{\mathrm{n}}\right)}{\left(\mathrm{v}_{\mathrm{n}}, \mathrm{v}_{\mathrm{n}}\right)} \mathrm{v}_{\mathrm{n}}
$$




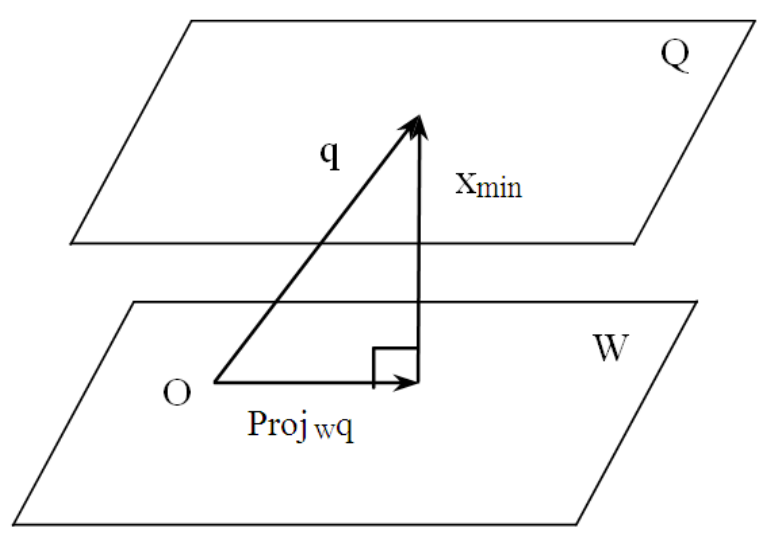

Fig. 1: The vector with smallest length

Theorem 2: Suppose $\mathrm{Q}=\{\mathrm{q}+\mathrm{w} \mid \mathrm{w} \in \mathrm{W}\}$ is an affine subspace of $\mathrm{L}$. A vector in $\mathrm{Q}$ with smallest length exists and it is unique:

$$
x_{\min }=q-\text { Projw }_{w} .
$$

The vector $x_{\min }$ is independent of the choice of $q$. Theorem 2 is illustrated in Fig. 1.

Now we return to portfolio analysis. By Theorem 1.a), $\mathrm{E}(\mathrm{x})=\mathrm{Mx}$. So the last two equations in (2) have this matrix form Eq. 4:

$$
\left\{\begin{array}{c}
\mathrm{Ux}=1 \\
\mathrm{Mx}=\mu
\end{array}\right.
$$

This is the corresponding homogeneous system Eq. 5:

$$
\left\{\begin{array}{l}
\mathrm{Ux}=0 \\
\mathrm{Mx}=0
\end{array}\right.
$$

Denote $\mathrm{Q}$ and $\mathrm{W}$ the sets of all solutions of the systems (4) and (5) respectively. So Q is an affine subspace of $\mathrm{H}$ and $\mathrm{W}$ is its corresponding linear subspace with dimension $\mathrm{N}-2$ (since $\mathrm{U}$ and $\mathrm{M}$ are independent). In case $\mathrm{N}=2$ only one portfolio has expected return $\mu$ for any $\mu \in \mathrm{R}$. So we consider the case $\mathrm{N} \geq 3$.

The affine subspace $\mathrm{Q}$ can be written as:

$$
\mathrm{Q}=\{\mathrm{q}+\mathrm{w} \mid \mathrm{w} \in \mathrm{W}\}
$$

for any solution q of the system (4).

Theorem 3: For any $\mu \in R$, there is a unique envelope portfolio with expected return $\mu$. It equals:

$$
\mathrm{x}_{\mu}=\mathrm{q}-\operatorname{Proj}_{\mathrm{w}} \mathrm{q},
$$

where $\mathrm{q}$ is any solution of (4).

Proof: An envelope portfolio $\mathrm{x}$ with expected return $\mu$ is a solution of the system (4) with smallest variance and

$\|\mathrm{x}\|^{2}=(\mathrm{x}, \mathrm{x})=\mathrm{E}\left(\mathrm{x}^{2}\right)=\operatorname{Var}(\mathrm{x})+[\mathrm{E}(\mathrm{x})]^{2}=\operatorname{Var}(\mathrm{x})+\mu^{2}$.

So the smallest variance means the smallest length, since $E(x)=\mu$ is fixed. Next apply Theorem 2 .

Theorem 4: Let $\mathrm{v}_{1}, \ldots, \mathrm{v}_{\mathrm{N}-2}$ be an orthogonal system of solutions of the system (5). Then

a) for any $y \in H,\left(y, v_{k}\right)=\operatorname{Cov}\left(y, v_{k}\right), k=1, \ldots, N-2$;

b) the envelope portfolio with expected return $\mu$ equals:

$$
\mathrm{x}_{\mu}=\mathrm{q}-\sum_{\mathrm{k}=1}^{\mathrm{N}-2} \frac{\left(\mathrm{q}, \mathrm{v}_{\mathrm{k}}\right)}{\left(\mathrm{v}_{\mathrm{k}}, \mathrm{v}_{\mathrm{k}}\right)} \mathrm{v}_{\mathrm{k}},
$$

where $\mathrm{q}$ is a solution of (4);

c) the envelope of the given assets is the set $\left\{x_{\mu} \mid \mu \in \mathrm{R}\right\}$, where $x_{\mu}$ is given by the previous formula.

Proof: a) Each $v_{k}$ is a solution of (5), so

$$
\mathrm{E}\left(\mathrm{v}_{\mathrm{k}}\right)=\mathrm{M} \mathrm{v}_{\mathrm{k}}=0 .
$$

For any $y \in H,\left(y, v_{k}\right)=E\left(y \cdot v_{k}\right)=\operatorname{Cov}\left(y, v_{k}\right)+$

$+\mathrm{E}(\mathrm{y}) \cdot \mathrm{E}\left(\mathrm{v}_{\mathrm{k}}\right)=\operatorname{Cov}\left(\mathrm{y}, \mathrm{v}_{\mathrm{k}}\right)+\mathrm{E}(\mathrm{y}) \cdot 0=\operatorname{Cov}\left(\mathrm{y}, \mathrm{v}_{\mathrm{k}}\right)$.

b) The system $v_{1}, \ldots, v_{N-2}$ is an orthogonal basis in $\mathrm{W}$, so the result follows from Theorem 3 and formula (3) for projection.

c) is obvious.

\section{Mean-variance relation:}

Definition 5: To each portfolio of assets $\mathrm{A}_{1}, \ldots, \mathrm{A}_{N}$ we can assign a pair $(\sigma, \mu)$ of its standard deviation and expected return. The set of all such pairs is called the feasible set of the assets $A_{1}, \ldots, A_{N}$.

The feasible set is represented by a figure on $(\sigma$, $\mu)$-plane. There is no one-to-one correspondence between portfolios and points of the feasible set because two different portfolios can have equal means and equal standard deviations.

Theorem 5: The envelope is represented on the $(\sigma, \mu)$ plane by the right branch of a hyperbola Eq. 6 :

$$
\left\{\begin{array}{c}
\frac{\sigma^{2}}{\mathrm{~A}}-\frac{\left(\mu-\mu_{0}\right)^{2}}{\mathrm{~B}}=1 \\
\sigma>0
\end{array}\right.
$$

for some constants $\mathrm{A}>0, \mathrm{~B}>0$ and $\mu_{0}$. 


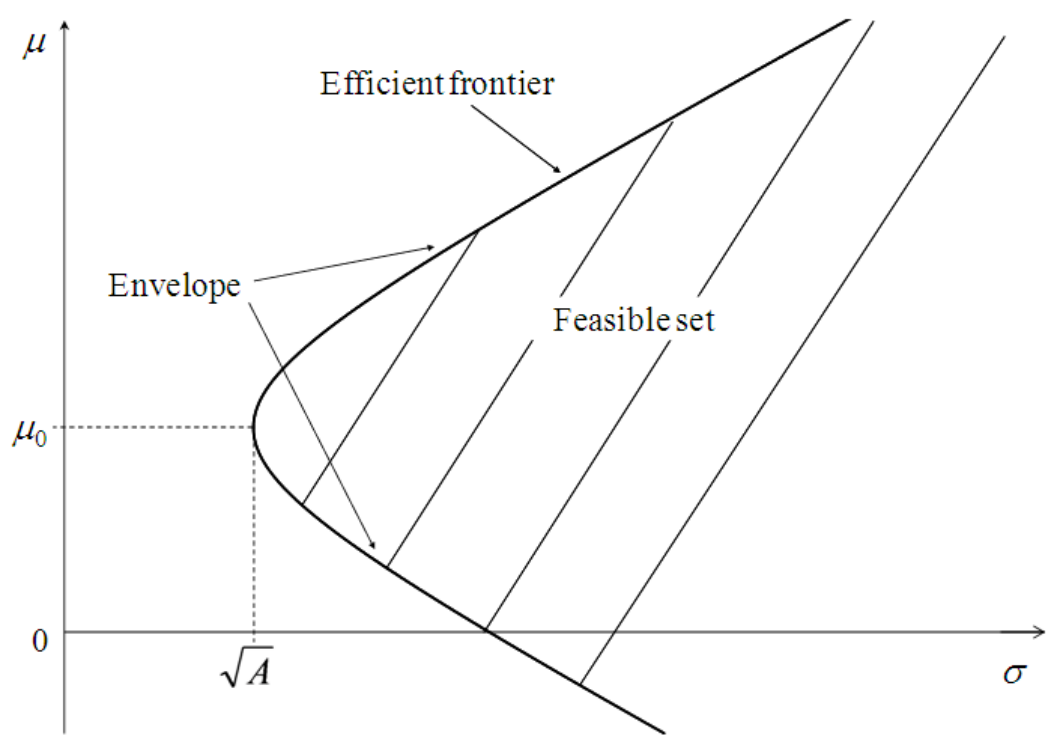

Fig. 2: The mean-variance relation

For $N \geq 3$, the feasible region is the region to the right of the curve (6) including the curve itself.

The portfolio with lowest risk corresponds to the vertex of the curve (6); it has the mean $\mu_{0}$ and the variance $\mathrm{A}$.

The efficient frontier is represented on the $(\sigma, \mu)$ plane by the top half of the curve (6):

$$
\left\{\begin{array}{l}
\frac{\sigma^{2}}{\mathrm{~A}}-\frac{\left(\mu-\mu_{0}\right)^{2}}{\mathrm{~B}}=1 \\
\sigma>0 \\
\mu \geq \mu_{0}
\end{array} .\right.
$$

Figure 2 illustrates Theorem 5.

Proof: a) Denote $x_{\mu}$ the envelope portfolio with expected return $\mu$ and denote $\sigma^{2}$ its variance. The system (4) of linear equations can be solved using Gauss-Jordan elimination, so any solution q is a linear function of the parameter $\mu$. From Theorem 4.b) it follows that the envelope portfolio $x_{\mu}$ is also a linear function of $\mu: x_{\mu}=c+b \mu$, where $c$ and $b$ are some vectors independent of $\mu, b \neq 0$.

By Theorem 1.b):

$\sigma^{2}=\operatorname{Var}\left(x_{\mu}\right)=x_{\mu}{ }^{T} \operatorname{Sx}_{\mu}=(c+b \mu)^{T} \cdot S \cdot(c+b \mu)=$

$=c^{\mathrm{T}} \mathrm{S} c+\mu^{2} b^{\mathrm{T}} \mathrm{Sb}+\mu\left(c^{\mathrm{T}} \mathrm{Sb}+\mathrm{b}^{\mathrm{T}} \mathrm{Sc}\right)$.

So the relation between $\mu$ and $\sigma$ for envelope portfolios is given by this second-degree equation:

$$
\sigma^{2} b^{T} S b+\mu\left(c^{T} S b+b^{T} S c\right)-\sigma^{2}+c^{T} S c=0 .
$$

Comparing this with the general equation of a second-degree curve:

$a_{11} u^{2}+2 a_{12} u v+a_{22} v^{2}+2 a_{13} u+2 a_{23} v+a_{33}=0$

we get $\mathrm{a}_{11}=\mathrm{b}^{\mathrm{T}} \mathrm{S} b, \mathrm{a}_{22}=-1, \mathrm{a}_{33}=\mathrm{c}^{\mathrm{T}} \mathrm{Sc}$,

$a_{13}=\frac{1}{2}\left(c^{\mathrm{T}} \mathrm{S} \mathrm{b}+\mathrm{b}^{\mathrm{T}} \mathrm{S} c\right), \mathrm{a}_{12}=\mathrm{a}_{23}=0$.

Consider two invariants $\mathrm{I}_{2}$ and $\mathrm{I}_{3}$.

$I_{2}=\left|\begin{array}{ll}a_{11} & a_{12} \\ a_{12} & a_{22}\end{array}\right|=a_{11} a_{22}-a_{12}^{2}=-b^{T} S b$.

$\mathrm{I}_{2}<0$, since the matrix $\mathrm{S}$ is positive definite.

$$
\begin{aligned}
& I_{3}=\left|\begin{array}{lll}
a_{11} & a_{12} & a_{13} \\
a_{12} & a_{22} & a_{23} \\
a_{13} & a_{23} & a_{33}
\end{array}\right|=\left|\begin{array}{ccc}
a_{11} & 0 & a_{13} \\
0 & -1 & 0 \\
a_{13} & 0 & a_{33}
\end{array}\right|=-\left|\begin{array}{ll}
a_{11} & a_{13} \\
a_{13} & a_{33}
\end{array}\right|= \\
& =\frac{1}{4}\left[\left(c^{\mathrm{T}} \mathrm{Sb}+b^{\mathrm{T}} \mathrm{Sc}\right)^{2}-4\left(\mathrm{~b}^{\mathrm{T}} \mathrm{Sb}\right)\left(c^{\mathrm{T}} \mathrm{Sc}\right)\right]
\end{aligned}
$$

Since the matrix $\mathrm{S}$ is positive definite, for any real number $\mathrm{t}$ :

Hence for any $t$ :

$$
(c+b t)^{T} S(c+b t)>0 .
$$




$$
\mathrm{t}^{2} \mathrm{~b}^{\mathrm{T}} \mathrm{Sb}+\mathrm{t}\left(\mathrm{c}^{\mathrm{T}} \mathrm{Sb}+\mathrm{b}^{\mathrm{T}} \mathrm{Sc}\right)+\mathrm{c}^{\mathrm{T}} \mathrm{Sc}>0 .
$$

So the discriminant of this quadratic is negative:

$$
\left(c^{\mathrm{T}} \mathrm{Sb}+\mathrm{b}^{\mathrm{T}} \mathrm{Sc}\right)^{2}-4\left(\mathrm{~b}^{\mathrm{T}} \mathrm{Sb}\right) \cdot\left(\mathrm{c}^{\mathrm{T}} \mathrm{Sc}\right)<0 .
$$

This implies $\mathrm{I}_{3}<0$. Also we have $\mathrm{I}_{2}<0$, therefore the equation (7) defines a non-degenerate hyperbola with the real axis parallel to $O \sigma$. The equation (7) can be transformed to a canonical form by completing the square for $\mu$, so the result has the form (6).

Since the curve (6) represents the envelope portfolios, all other portfolios have higher variances, so their corresponding $(\sigma, \mu)$-points lie to the right of the curve.

From the equation (6) we see that the right vertex of the hyperbola has coordinates $\left(\mu_{0}, \sqrt{\mathrm{A}}\right)$; it corresponds to the portfolio with the lowest risk.

As Figure 2 shows, each feasible value of $\sigma$ (except the vertex value) corresponds to two points on the envelope and two values of $\mu$. The point with a higher $\mu$ is on the efficient frontier.

Example with four assets: Consider four assets with expected returns of $1,1,2$ and $1 \%$ respectively. Their covariance matrix:

$$
S=\left[\begin{array}{rrrr}
1 & 1 & 0 & -1 \\
1 & 2 & 1 & -1 \\
0 & 1 & 2 & 0 \\
-1 & -1 & 0 & 2
\end{array}\right]
$$

- Find the envelope of these assets

- On the mean-variance plane find

- The envelope and (ii) the feasible region

- Find the portfolio with lowest risk

- Find the efficient frontier of the assets

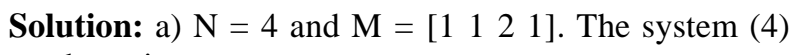
can be written as:

$$
\left\{\begin{array}{c}
x_{1}+x_{2}+x_{3}+x_{4}=1 \\
x_{1}+x_{2}+2 x_{3}+x_{4}=\mu
\end{array}\right.
$$

$\mathrm{q}=\left[\begin{array}{c}0 \\ 0 \\ \mu-1 \\ 2-\mu\end{array}\right]$ is one of its solutions.
This is the corresponding homogeneous system:

$$
\left\{\begin{array}{c}
x_{1}+x_{2}+x_{3}+x_{4}=0 \\
x_{1}+x_{2}+2 x_{3}+x_{4}=0
\end{array}\right.
$$

And one of its non-trivial solutions: $v_{1}=\left[\begin{array}{r}1 \\ -1 \\ 0 \\ 0\end{array}\right]$

Consider its another non-trivial solution $v_{2}=\left[\begin{array}{c}x_{1} \\ x_{2} \\ x_{3} \\ x_{4}\end{array}\right]$ orthogonal to $\mathrm{v}_{1}$.

Then $0=\left(\mathrm{v}_{1}, \mathrm{v}_{2}\right)=[$ by Theorem $\left.4 . \mathrm{a})\right]=$

$=\operatorname{Cov}\left(\mathrm{v}_{1}, \mathrm{v}_{2}\right)=\mathrm{v}_{1}{ }^{\mathrm{T}} \mathrm{S} \mathrm{v}_{2}=$

$=\left[\begin{array}{llll}1 & -1 & 0 & 0\end{array}\right]\left[\begin{array}{rrrr}1 & 1 & 0 & -1 \\ 1 & 2 & 1 & -1 \\ 0 & 1 & 2 & 0 \\ -1 & -1 & 0 & 2\end{array}\right]\left[\begin{array}{c}x_{1} \\ x_{2} \\ x_{3} \\ x_{4}\end{array}\right]=-x_{2}-x_{3}$.

Thus, $v_{2}$ should satisfy these three equations:

$$
\left\{\begin{array}{c}
x_{1}+x_{2}+x_{3}+x_{4}=0 \\
x_{1}+x_{2}+2 x_{3}+x_{4}=0, v_{2} \\
-x_{2}-x_{3}=0
\end{array}=\left[\begin{array}{r}
1 \\
0 \\
0 \\
-1
\end{array}\right]\right.
$$

By Theorem 4.b), $\mathrm{x}_{\mu}=\mathrm{q}-\frac{\left(\mathrm{q}, \mathrm{v}_{1}\right)}{\left(\mathrm{v}_{1}, \mathrm{v}_{1}\right)} \mathrm{v}_{1}-\frac{\left(\mathrm{q}, \mathrm{v}_{2}\right)}{\left(\mathrm{v}_{2}, \mathrm{v}_{2}\right)} \mathrm{v}_{2}$.

$\left(\mathrm{q}, \mathrm{v}_{1}\right)=\operatorname{Cov}\left(\mathrm{q}, \mathrm{v}_{1}\right)=\mathrm{q}^{\mathrm{T}} \mathrm{S} \mathrm{v}_{1}=$

$=\left[\begin{array}{llll}0 & 0 & \mu-1 & 2-\mu\end{array}\right]\left[\begin{array}{rrrr}1 & 1 & 0 & -1 \\ 1 & 2 & 1 & -1 \\ 0 & 1 & 2 & 0 \\ -1 & -1 & 0 & 2\end{array}\right]\left[\begin{array}{r}1 \\ -1 \\ 0 \\ 0\end{array}\right]=1-\mu$.

Similarly, $\left(\mathrm{q}, \mathrm{v}_{2}\right)=\operatorname{Cov}\left(\mathrm{q}, \mathrm{v}_{2}\right)=\mathrm{q}^{\mathrm{T}} \mathrm{S} \mathrm{v}_{2}=3 \mu-6$;

$\left(\mathrm{v}_{1}, \mathrm{v}_{1}\right)=\operatorname{Var}\left(\mathrm{v}_{1}\right)=\mathrm{v}_{1}{ }^{\mathrm{T}} \mathrm{S} \mathrm{v}_{1}=1$;

$\left(\mathrm{v}_{2}, \mathrm{v}_{2}\right)=\operatorname{Var}\left(\mathrm{v}_{2}\right)=\mathrm{v}_{2}{ }^{\mathrm{T}} \mathrm{S} \mathrm{v}_{2}=5$. 


$$
\begin{aligned}
& \text { So } \mathrm{x}_{\mu}=\mathrm{q}-\frac{\left(\mathrm{q}, \mathrm{v}_{1}\right)}{\left(\mathrm{v}_{1}, \mathrm{v}_{1}\right)} \mathrm{v}_{1}-\frac{\left(\mathrm{q}, \mathrm{v}_{2}\right)}{\left(\mathrm{v}_{2}, \mathrm{v}_{2}\right)} \mathrm{v}_{2}= \\
& =\left[\begin{array}{c}
0 \\
0 \\
\mu-1 \\
2-\mu
\end{array}\right]+(\mu-1)\left[\begin{array}{r}
1 \\
-1 \\
0 \\
0
\end{array}\right]-\frac{3 \mu-6}{5}\left[\begin{array}{c}
1 \\
0 \\
0 \\
-1
\end{array}\right], \mathrm{x}_{\mu}=\frac{1}{5}\left[\begin{array}{c}
2 \mu+1 \\
-5 \mu+5 \\
5 \mu-5 \\
-2 \mu+4
\end{array}\right] \\
& \operatorname{Env}\left(A_{1}, A_{2}, A_{3}, A_{4}\right)=\left\{\frac{1}{5}\left[\begin{array}{c}
2 \mu+1 \\
-5 \mu+5 \\
5 \mu-5 \\
-2 \mu+4
\end{array}\right] \mid \mu \in R\right\} . \\
& \text { The variance of } \mathrm{x}_{\mu} \text { is } \sigma^{2}=\mathrm{x}_{\mu}^{\mathrm{T}} \mathrm{Sx}_{\mu}= \\
& =\frac{1}{5}\left(6 \mu^{2}-14 \mu+9\right) \text {. }
\end{aligned}
$$

The envelope is represented on the mean-variance plane by the curve: $6 \sigma^{2}-14 \mu+9=5 \sigma^{2}$. After completing the square we have:

$$
5 \sigma^{2}-6\left(\mu-\frac{7}{6}\right)^{2}=\frac{5}{6} .
$$

Changing this to canonical form we get this equation for the envelope:

$$
\frac{\sigma^{2}}{\frac{1}{6}}-\frac{\left(\mu-\frac{7}{6}\right)^{2}}{\frac{5}{36}}=1(\sigma>0) \text {. }
$$

The feasible region is the region to the right of the curve (9) including the curve, so it is given by:

$$
\sigma \geq \sqrt{\frac{36\left(\mu-\frac{7}{6}\right)^{2}+5}{30}}
$$

The portfolio $x_{0}$ with the lowest risk corresponds to the right vertex of the hyperbola (9), which has the coordinates $\left(\frac{7}{6}, \frac{1}{\sqrt{6}}\right)$. So the parameters of $x_{0}$ are: $\mu_{0}=\frac{7}{6}$ and $\sigma_{0}=\frac{1}{\sqrt{6}}$. Substituting $\mu=\frac{7}{6}$ into (8) we $\mathrm{x}_{0}=\frac{1}{6}\left[\begin{array}{r}4 \\ -1 \\ 1 \\ 2\end{array}\right]$ get , the portfolio with the lowest risk.
The efficient frontier is the top half of the curve (9). On the mean-variance plane it is given by:

$$
\begin{aligned}
& \left\{\begin{array}{c}
\frac{\sigma^{2}}{\frac{1}{6}}-\frac{\left(\mu-\frac{7}{6}\right)^{2}}{\frac{5}{36}}=1 \\
\sigma>0 \\
\mu \geq \frac{7}{6}
\end{array}\right. \\
& \operatorname{EF}\left(A_{1}, A_{2}, A_{3}, A_{4}\right)=\left\{\frac{1}{5}\left[\begin{array}{c}
2 \mu+1 \\
-5 \mu+5 \\
5 \mu-5 \\
-2 \mu+4
\end{array}\right] \mid \mu \geq \frac{7}{6}\right\} .
\end{aligned}
$$

\section{CONCLUSION}

Usually problems in financial mathematics are solved using calculus and probability methods. In this study we described a geometric solution of a problem in portfolio analysis. This method can be used in university courses on financial mathematics. The method simplifies proofs and it is invariant while the old method uses coordinates and is quite long.

With the invariant geometric approach the students can focus more on the conceptual part of the topic instead of the technical details and link abstract concepts of linear algebra to practical applications in finance.

\section{REFERENCES}

Benninga, S. and B. Czaczkes, 2000. Financial Modeling. 2nd Edn., MIT Press, Cambridge, MA.,. ISBN-10: 0262024829, pp: 622.

Cheang, G.H.L. and Y. Zhao, 2005. Calculus and Matrix Algebra for Finance. 3rd Edn., McGrawHill, New York, ISBN: 0071249532, pp: 207.

Francis, J.C. and R.W. Taylor, 2000. Schaum's Outline of Investments. 2nd Edn., McGraw-Hill, New York, ISBN-10: 0071348492, pp: 330.

Grimmett, G. and D. Stirzaker, 2001. Probability and Random Processes. 3rd Edn., Oxford University Press, New York, ISBN-10: 0198572220, pp: 596.

Kachapova, F. and I. Kachapov, 2005. Calculating optimal portfolios of three financial assets. Math. Inform. Q., 15: 100-107.

Kachapova, F. and I. Kachapov, 2006. Mathematical Approach to Portfolio Analysis. 1st Edn., Maths Ken, Auckland, ISBN-10: 0473111942, pp: 149. 
Kachapova, F. and I. Kachapov, 2010. Orthogonal projection in teaching regression and financial mathematics. J. Stat. Educ., 18: 1-18.
Teall, J.L. and I. Hasan, 2002. Quantitative Methods for Finance and Investments. 1st Edn., WileyBlackwell, Oxford, ISBN: 0631223398. pp: 276. 